\title{
Os conceitos de Espaço, Território e Estado numa perspectiva político-geográfica dos Investimentos Estrangeiros Diretos no Estado do Paraná ${ }^{1}$
}

Concepts of space, territory and State in a political-geographical perspective of foreign direct investment in the State of Paraná

Gustavo Glodes Blum²

\section{RESUMO}

Através do presente trabalho buscamos realizar uma aproximação teórica que facilite a compreensão dos processos de Investimento Estrangeiro Direto (IEDs) no Estado do Paraná através dos conceitos de Espaço, Território e Estado. Através desta perspectiva político-geográfica, compreendemos a sua utilização e viabilidade na análise no caso apresentado.

Palavras-chave: Espaço e Território; Paraná; Investimento Estrangeiro Direto.

\begin{abstract}
Through this paper we seek to create a theoretical approach that can allow a better understanding of the Foreign Direct Investment (FDI) processes occurring in the State of Paraná, Brazil. For that, we analyze the concepts of Space, Territory and State. Through this political and geographic perspective, we understand the usefulness of these concepts and their viability in the analysis of the presented case study.
\end{abstract}

Keywords: Space and Territory; Paraná; Foreign Direct Investment.

\section{Introdução}

O presente trabalho faz uma breve aproximação teórica, baseando-se principalmente nos conceitos da Geografia Política, a respeito das relações entre Estado, Território e a instalação de Investimentos Estrangeiros Diretos (IEDs) no Estado do Paraná. As indicações aqui realizadas têm a intenção de verificar conceitualmente estas

\footnotetext{
${ }^{1}$ Artigo recebido em 11 de março de 2014 e aprovado em 31 de março de 2014.

${ }^{2}$ Membro do Programa de Pós-Graduação em Geografia, no curso de Mestrado, da Universidade Federal do Paraná (UFPR), Especialista em Gestão de Projetos pela FAE Business School e Bacharel em Relações Internacionais pelo Centro Universitário Curitiba (Unicuritiba). Atualmente, é Professor Assistente Especialista na Unicuritiba, responsável pela disciplina de Geopolítica do curso de Relações Internacionais, e Bolsista da Coordenação de Aperfeiçoamento do Pessoal do Ensino Superior (CAPES).
}

Conjuntura Global, Vol.3, n.1, jan./mar., 2014, p. 28-42. 
relações, e verificar como sua aplicação pode contribuir nos rumos de pesquisas desta natureza.

Desenvolvido no âmbito do Programa de Pós-Graduação em Geografia da Universidade Federal do Paraná (PPGGeografia/UFPR), este trabalho surge após as leituras e debates desenvolvidos na disciplina "Estado e Território no Brasil", sob orientação do Prof. Dr. Adilar Cigolini, assim como da pesquisa estabelecida sob orientação do Prof. Dr. Nilson Cesar Fraga.

Inicialmente, estabelecemos nossa forma de compreensão a respeito das relações sociais em sua materialidade espacial e na construção de territórios diversos. A seguir, discutimos análises possíveis a respeito da noção de economia política do Território, para podermos, ao final, abordar algumas problematizações de matriz política, econômica e territorial no caso do Estado do Paraná.

\section{Materializando as relações sociais e o poder: Espaço e Território}

Em busca de uma maior compreensão a respeito das articulações entre a estrutural estatal e as empresas transnacionais que realizaram IEDs recentemente no Estado do Paraná, consideramos relevante apresentar os conceitos de Espaço e Território conforme apresentados pela Geografia e, especificamente, pela Geografia Política. Ambos os conceitos são importantes para esta compreensão, uma vez que representam um dos aspectos estudados pela ciência, ou seja, a materialização das relações sociais e de poder.

Compreendemos, em conjunto com Claude Raffestin (1993), que uma análise das relações sociais e, sobretudo, as relações de poder, deve se dar tendo em mente alguns elementos básicos, ou seja, os elementos constitutivos daquilo que denominamos "relações":

\footnotetext{
Os elementos constitutivos [da relação] são: os atores, a política dos atores - ou o conjunto de suas intenções, isto é, suas finalidades -, a estratégia deles para chegar a seus fins, os mediatos da relação, os diversos códigos utilizados e os componentes espaciais e temporais da relação (RAFFESTIN, 1993, p. 38).
}

Raffestin nos apresenta, através da enumeração dos elementos constitutivos da relação, os parâmetros para a sua análise. Levamos isso em consideração em razão de

Conjuntura Global, Vol.3, n.1, jan./mar., 2014, p. 28-42. 
nossa perspectiva a respeito dos processos que ocorrem tanto no Espaço como no Território. Em nossa análise, levamos em consideração esse aspecto relacional, que permite aproximar todos estes elementos, além de ter a noção de que a ação de determinados atores políticos está envolta, também num contexto que se define por estes elementos. Os atores envolvidos em qualquer processo político e territorial são responsáveis pela articulação contínua entre Poder, Espaço e Território - no caso específico deste estudo, as diversas relações de poder exercidas durante a realização de IEDs no Paraná. Ora, o processo de transformação de um espaço em um território, dentro da tradição científica geográfica, está inexoravelmente relacionado com a materialização de redes de poder, que dominam, materializam alterações e reproduzem socialmente a sociedade (SANTOS; SILVEIRA, 2012).

Consideramos que a perspectiva de Milton Santos nos auxilia a problematizar a questão, sobretudo para compreendermos a relação entre Espaço e Território, que se dá através do Poder. Segundo o autor, "o espaço é formado de objetos", onde se relacionam o processo de produção ("trabalho") e de circulação dentro deste mesmo espaço, relacionando estes objetos com o tempo de circulação e o lugar da produção (SANTOS, 2005, p. 55). Ao mesmo tempo, devemos considerar o Espaço como sendo:

\footnotetext{
(...) formado por um conjunto indissociável, solidário e também contraditório de sistemas de objetos e sistemas de ações, não considerado isoladamente, mas como o quadro único no qual a história se dá. No começo era a natureza selvagem, formada de objetos naturais, que ao longo da história vão sendo substituídos por objetos fabricados, objetos técnicos, mecanizados e, depois, cibernéticos, fazendo com que a natureza artificial tenda a funcionar como uma máquina. Através da presença desses objetos técnicos: hidroelétricas, fábricas, fazendas modernas, portos, estradas de rodagem, estradas de ferro, cidades, o espaço é marcado por esses acréscimos, que lhe dão um conteúdo extremamente técnico (SANTOS, 2005, p. 63).
}

Assim, o Espaço se caracteriza como este conjunto de objetos dispostos na superfície, sendo eles naturais ou construídos artificialmente pelo Homem. É este conjunto de objetos, que se relacionam entre si, que dá a característica a esse Espaço: a relação entre Natureza, trabalho/produção e circulação, onde o Homem exerce sobre seu espaço natural, que anteriormente o continha, alterações que são a reflexão e a materialidade das relações de poder estabelecidas naquela sociedade. 
Ora, realizar esta afirmação é considerar a alteração conceitual de quando debatemos Espaço e Território, uma vez que problematizar o segundo envolve necessariamente compreender quais são as relações sociais que se dão no primeiro, enquanto base material para a existência. Como afirma Marcelo José Lopes de Souza, o Território é um espaço, ou seja, um conjunto de sistemas de objetos e sistemas que ações que se dão envolvendo-os, marcado por relações de poder:

O território, (...) é fundamentalmente um espaço definido e delimitado por e a partir de relações de poder. A questão primordial, aqui, não é, na realidade, quais são as características geoecológicas e os recursos naturais de uma certa área, o que se produz ou quem produz em um dado espaço, ou ainda quais as ligações afetivas e de identidade entre um grupo social e seu espaço. (...) o verdadeiro Leitmotiv ${ }^{3}$ é o seguinte: quem domina ou influencia e como domina ou influencia esse espaço? Esse Leitmotiv traz embutida ao menos de um ponto de vista não interessado em escamotear conflitos e contradições sociais, a seguinte questão inseparável, uma vez que o território é essencialmente um instrumento de exercício de poder: quem domina ou influencia quem nesse espaço, e como? (SOUZA, 2012, pp. 78-79; grifo no original).

Territorializar o espaço, portanto, passa pela percepção de que as relações sociais, e de poder, estão aplicadas nos grupos sociais que habitam determinado espaço. Determinar esta relação, porém, não significa decantá-la a fim de obter uma apenas definição, uma vez que, no pensamento geográfico, o conceito de Território é polissêmico, como diz Rogério Haesbert (2011). Segundo o autor, existem três vertentes de análise do Território, sendo que cada uma leva em conta formas diversas deste processo de apropriação do espaço em suas características "lineares, areais ou zonais" (p. 40).

As três vertentes às quais Haesbaert se refere são a vertente política ou jurídicopolítica, a vertente cultural ou culturalista, e a vertente econômica ou economicista. Enquanto a vertente cultural dá mais ênfase às dimensões simbólicas em que o Território é percebido como produto da "apropriação/valoração simbólica de um grupo em relação ao seu espaço vivido", a vertente economicista, ainda que menos difundida, "enfatiza a dimensão das relações econômicas, o território como fonte de recursos e/ou incorporado no embate entre classes sociais e na relação capital-trabalho, como produto da divisão 'territorial' do trabalho, por exemplo" (idem). Por fim, a vertente política é

\footnotetext{
${ }^{3}$ Em tradução livre, "tema principal".
}

Conjuntura Global, Vol.3, n.1, jan./mar., 2014, p. 28-42. 
aquela que analisa o Território enquanto "um espaço delimitado e controlado, através do qual se exerce um determinado poder, na maioria das vezes - mas não exclusivamente - relacionado ao poder político do Estado" (idem).

Estas três perspectivas têm como pano de fundo, como podemos perceber, as relações sociais. Seja na apropriação cultural do espaço, seja na percepção de que o Território pode ser compreendido através de uma análise baseada na economia, ou no exercício de um poder juridicamente estabelecido (mas não apenas), todas se referem a uma perspectiva que deveria ser pensada da forma relacional à qual Claude Raffestin (1993) se refere. Para o autor, o estudo da Geografia não deve se referir apenas ao poder instituído e juridicamente legal - tradicionalmente o poder do Estado ${ }^{4}$ - mas sim nas diversas relações de poder estabelecidas nas sociedades:

Uma verdadeira geografia só pode ser uma geografia do poder ou dos poderes. Para nós, a expressão geografia do poder é bem mais adequada e nós a utilizaremos daqui para frente. Se dissermos, seguindo [Henri] Lefébvre, que só existe poder político, isto significa, levando-se em consideração o que precedeu, que o fato político não está inteiramente refugiado no Estado. Com efeito, se o fato político atinge a sua forma mais acabada no Estado, isto não implica que não caracterize outras comunidades (...). Admitimos que há poder político desde o momento em que uma organização luta contra a entropia que a ameaça de desordem. Esta definição, inspirada em [Georges] Balandier nos faz descobrir que o poder político é congruente a toda forma de organização. Ora, a geografia política, no sentido estrito do termo, deveria levar em consideração as organizações que se desenvolvem num quadro espaço-temporal que contribuem para organizar ou... para desorganizar (RAFFESTIN, 1993, pp. 1718).

Assim, podemos compreender de qual forma, enquanto falamos nas relações sociais, podemos falar em relações políticas. Se pensamos, em consonância com Norberto Bobbio (1987, pp. 62-67) que o Estado tem se tornado cada vez mais um subsistema da sociedade como um todo, concordamos com o fato de que ele não está sobre ou fora da mesma, mas sim inserido nos processos sociais. 0 que ocorre, de forma regular nos processos sociais, é que o Estado é, sempre, um ator assimétrico de acordo com o que Raffestin define:

\footnotetext{
${ }^{4}$ Segundo Claude Raffestin, "O poder, nome comum, se esconde atrás do Poder, nome próprio. (...) [0 Poder, com letra maiúscula] é mais fácil de cercar porque se manifesta por intermédio dos aparelhos complexos que encerram o território, controlam a população e dominam os recursos. É o poder visível, maciço, identificável. (...) [0] poder [com letra minúscula] torna-se perene, por não é mais visível, é consubstancial com todas as relações. (...) 0 poder é parte intrínseca de toda relação. Multidimensionalidade e imanência do poder em oposição à unidimensionalidade e à transcendência: '0 poder está em todo lugar, não que englobe tudo, mas vem de todos os lugares'." (1993, p. 52)
}

Conjuntura Global, Vol.3, n.1, jan./mar., 2014, p. 28-42. 
Teoricamente, a simetria, pela existência de uma equivalência real, impede o crescimento de uma organização ou de uma estrutura em detrimento de uma outra; impede também a destruição de uma organização ou de uma estrutura por uma outra. A simetria é responsável pela diferença e pelo pluralismo. Em contrapartida, também de maneira teórica, a dissimetria, por equivalência forçada, favorece o crescimento de uma estrutura em detrimento de outra e, num extremo, a destruição de uma estrutura por outra (RAFFESTIN, 1993, p. 36).

A simetria se define por uma relação igualitária - de onde Raffestin tira a ideia do "reconhecimento das necessidades do Outro". A dissimetria, por sua vez, "só reconhece a existência de suas necessidades na medida em que aceita o jogo das equivalências forçadas" (idem). Desta forma, compreendemos que as diversas relações de poder se dão de forma simétrica ou assimétrica de acordo com os recursos utilizados e valorados como definidores deste reconhecimento de necessidades. ${ }^{5}$ É assim que podemos compreender a atuação do Estado não apenas com relação á sua população, mas também à sua língua e ao seu território, dentro da perspectiva da dissimetria do autor.

Se observarmos a sociedade a partir de três subsistemas, organizados na área econômica (forças produtivas), na área ideológica (consenso) e na área política (o Estado, poder coativo) (BOBBIO, 1987, p. 83), podemos compreender de qual forma se dão as interações que não apenas são capazes de materializar as formas de poder estabelecidas na relação, mas também têm resultado na vida da sociedade como um todo. Uma vez que estas áreas entram em contato e, não raramente, os superiores de uma forma de poder influenciam os outros superiores (quando não são identificáveis como o mesmo grupo social), pode-se obter que, não raro, existe um tipo de concertação entre estes grupos, gerando resultados positivos a si, mas com consequências diversas para os outros membros daquela sociedade.

\footnotetext{
${ }^{5}$ Bobbio (1987) apresenta a tipologia mais utilizada para compreender o fenômeno do poder na teoria política: o poder político, baseado no domínio legítimo da força e o comando da população sobre um determinado território; o poder econômico, baseado no acúmulo de riqueza entre os diversos elementos considerados; e o poder ideologia, baseado no conhecimento (pp. 82-83). Segundo o autor, estas três formas de poder permitem uma análise de uma possível divisão entre os diversos atores sociais, entre fortes e fracos no poder político, ricos e pobres no poder econômico, e sábios e ignorantes no caso do poder ideológico. Raffestin apresenta a ideia de que, sendo o poder consubstancial a qualquer relação, este tipo de tipificação demonstra o meio utilizado, uma vez que não diferenciação entre os tipos de poder, mas sim as formas como ele se exerce (1993).
}

Conjuntura Global, Vol.3, n.1, jan./mar., 2014, p. 28-42. 
É desta forma que podemos compreender de qual forma a política se torna um meio efetivo de poder. Na próxima seção, verificaremos de qual forma se dá a relação entre o poder econômico e o poder político na organização do território, aplicada ao caso do Brasil.

\section{ESTADO E ECONOMIA POLÍTICA DO TERRITÓRIO}

O pensamento político brasileiro já se debruçou sobre a questão da ocupação territorial do país. Considerado muitas vezes como uma questão estratégica, a disposição populacional no Brasil foi motivo de grandes questionamentos teóricos e produção de subsídios intelectuais à máquina administrativa (MIYAMOTO, 1995). Ao mesmo tempo, dependendo da análise realizada, ela pôde ser considerada como uma das formas pelas quais se dá a projeção internacional do país (COSTA, 2009[1992]).

A questão da geopolítica interna do Brasil sempre levou em consideração não apenas a implantação de núcleos determinados de povoamento, mas criar aquilo que Shiguenoli Miyamoto indica como "integração nacional": "Se entendemos a geopolítica como a utilização da fatores geográficos e sua aplicação na formulação de uma política visando principalmente a fins estratégicos, torna-se compreensível por que têm sido constantemente debatidos" (MIYAMOTO, op. cit., p. 145). Segundo o autor, seriam quatro os principais temas levantados pela Geopolítica brasileira: a geopolítica dos transportes, a mudança da capital federal, a geopolítica das fronteiras, e a redivisão territorial do Brasil. Destes aspectos, alguns se tornaram, efetivamente, políticas de governo ou de Estado, enquanto algumas permaneceram nos escaninhos das burocracias estatais (p. 146).

Estes três aspectos têm como intenção, além da ocupação efetiva e duradoura dos espaços nacionais por cidadãos brasileiros, levar para estas regiões um determinado tipo de lógica econômica, na qual pode se compreender aquilo que Milton Santos e María Silveira identificam como uma economia política do território (SANTOS; SILVEIRA, 2011). 
Falar em uma economia política do território significa admitir uma ordem espacial que está determinada e se desenvolve de acordo com alguns preceitos préestabelecidos de acordo com a lógica econômica: "Quando falamos de ordem espacial, estamos novamente nos referindo ao espaço explicado pelo seu uso" (SANTOS; SILVEIRA, 2011, p. 289). Retomando a caracterização do espaço como um sistema de objetos e um sistema de ações que se comunicam, trata de "caracterizar uma situação na qual, em cada área, os objetos tendem a exercer certas funções e os respectivos processos são, em grande parte, submetidos ao papel regulador de instituições [governamentais] e empresas" (idem).

No desenvolvimento de sua lógica funcional econômica, "cada atividade ou cada empresa produz a sua própria divisão do trabalho. Cada empresa, cada atividade necessita de pontos e áreas que constituem a base territorial de sua existência, como dados da produção e da circulação e do consumo" (SANTOS; SILVEIRA, 2011, p. 290). Uma vez que o pensamento e a ação das empresas se dão de acordo com a ampliação de seu escopo de atividade - incluindo uma escala geográfica cada vez maior à medida que a cadeia produtiva da mesma esteja ligada através de espaços locais, regionais, nacionais ou globais de redes, como indica Manuel Castells ${ }^{6}$ (1999), estas acabam por observar e atuar com relação ao espaço de acordo com a visão do estrategista definida por Claude Raffestin:

\begin{abstract}
O "estrategista" não vê o terreno; mais ainda, só deve vê-lo conceitualizado, senão não agiria. É à distância que sua ação é possível e, desde então, essa distância é a única a criar o "espaço" (...). E, de fato, criado pelo conceito de ação, que pode ser a guerra, mas que também pode ser de qualquer tipo de organização, de distribuição, de malha ou de corte. 0 estrategista não vê o terreno, mas a sua representação. Eis o porquê de esses elementos do código sintático, que são a dimensão, a forma e a posição, permanecerem essenciais na linguagem do território, mas devem ser retomados como plano de expressão de uma semiologia conotativa (p. 25).
\end{abstract}

\footnotetext{
${ }^{6}$ Segundo Castells, o espaço de redes ou de fluxos, "Está localizado em uma rede eletrônica, mas essa rede conecta lugares específicos com características sociais, culturais, físicas e funcionais bem definidas. Alguns lugares são intercambiadores, centros de comunicação desempenhando papel coordenador para a perfeita interação de todos os elementos integrados na rede. Outros lugares são os nós ou centros da rede, isto é, a localização de funções estrategicamente importantes que constroem uma série de atividades e organizações locais em torno de uma função chave na rede. A localização no nó conecta a localidade com toda a rede. Os nós e os centros de comunicação seguem uma hierarquia organizacional de acordo com seu peso relativo na rede. Mas essa hierarquia pode mudar dependendo da evolução das atividades processadas. Na verdade, em alguns casos, alguns lugares podem ser desconectados da rede, e seu desligamento resulta em um declínio imediato e, portanto, em deterioração econômica, social e física. As características dos nós dependem do tipo de funções desempenhadas por uma rede determinada" (1999, p. 502).
}

Conjuntura Global, Vol.3, n.1, jan./mar., 2014, p. 28-42. 
Tanto empresas como o Estado, na perspectiva das obras públicas, observam o terreno a partir do pensamento "estratégico" como definido por Raffestin. Trata-se de sublimar os conteúdos sociais do território, observando-o como espaço, para então agir, e realizar os cálculos que basearão a engenharia de organização da melhor forma para o subsistema produtivo. Individualmente, cada empresa busca a sua forma de melhor atuar, obtendo o melhor ganho, também em aspectos geográficos criando, porém, uma lógica que arrasta, também, outras empresas envolvidas na sua cadeia produtiva:

Cada empresa, cada ramo da produção produz, paralelamente, uma lógica territorial. (...) esta é visível por meio do que se pode considerar uma topologia, isto é, a distribuição no território dos pontos de interesse para a operação desta empresa. Esses pontos de interesse ultrapassam o âmbito da própria firma para se projetar sobre as empresas fornecedoras, ou compradoras, ou distribuidoras (SANTOS; SILVEIRA, op. cit., p. 292).

Ao criar esta lógica de uso espacial, a atividade econômica acaba criando, em si também, e dentro da mesma categoria - a de empresas - uma diferenciação entre aquelas que detêm maior poder e aquelas que detém menor poder. Aquelas que têm maior riqueza, ou melhores condições de acesso ao mercado, ou um maior mercado consumidor e, portanto, uma possibilidade maior de crescimento dos seus lucros, podem assumir o "papel de comando" deste processo de definição das estruturas físicas da economia, uma vez que os pontos geográficos da sua atuação se constituem nas suas bases de operação, e sua conexão é de extrema importância para a continuidade do crescimento nas vendas e obtenção dos lucros (SANTOS; SILVEIRA, op. cit., p. 291).

Assim, podemos compreender que o uso do espaço, e o controle que se exerce sobre ele, pode ser considerado, em si, uma forma de poder exercido pelas empresas. Como afirmam Santos e Silveira,

(...) o poder [corporativo] pode ser definido como a capacidade de uma organização para controlar os recursos que lhe são necessários, mas que também são necessários às outras organizações. (...) A noção de espaço corporativo deriva de tal mecanismo, que inclui uma utilização privilegiada dos bens públicos e uma utilização hierárquica dos bens privados [ou seja, as empresas se utilizam das obras do poder público, enquanto as maiores ficam com o melhor dos fornecedores privados]. (...) A partir destes dados, as maiores empresas passam a desempenhar um papel central na produção e no

Conjuntura Global, Vol.3, n.1, jan./mar., 2014, p. 28-42. 
funcionamento do território e da economia (...) pois sua hegemonia impõe uma acomodação forçada (p. 295).

Desta forma, podemos compreender como se dá a relação entre as empresas entre si e o poder público. Uma vez que o segundo é exortado a estabelecer melhorias em infraestrutura para o bom funcionamento das primeiras, existe um processo de associação que, inclusive, se desenvolve através de um discurso na escala global de que o bom desenvolvimento das diversas regiões no mundo (desenvolvimento este definido como uma perspectiva de crescimento econômico contábil) se dá através da aceitação de uma lógica global e imperativa de instalações de empresas internacionais no território (FERNÁNDEZ et al., 2008).

Para suscitar questionamentos a respeito desta realidade no Paraná, abordaremos na próxima seção (e última do trabalho aqui apresentado), de qual forma esta discussão se reflete atualmente no Estado.

\section{GOVERNO ESTADUAL E INVESTIMENTOS ESTRANGEIROS DIRETOS NO PARANÁ: PROBLEMATIZAÇÕES DE MATIZ POLÍTICA, ECONÔMICA E TERRITORIAL}

O Estado do Paraná têm conhecido, desde o início de seu povoamento, uma série de ciclos econômicos que se relacionam tanto com seu processo de constituição como a exploração e constituição do seu território atual (MAGALHÃES FILHO, 2011). Da mesma forma, o Paraná, enquanto entidade político-administrativa ou enquanto espaço de vivência da sua população, esteve sempre ligado com processos de povoamento e exploração do seu espaço com efeitos regionais, mas que estavam ligados com fluxos internacionais e nacionais. Desde a região do seu litoral até a fronteira estabelecida com a Argentina, o processo de inserção da exploração do território e o povoamento do mesmo sempre estiveram em conjunto:

O Estado do Paraná é caracterizado, historicamente, por um povoamento que teve orientação nas diversas fases econômicas pelas quais percorreu (tropeirismo, madeira, mate, café e soja). Essas fases resultaram num processo de povoamento irregular, no qual parcelas do território foram sendo ocupadas segundo as motivações de exploração econômica do território (FAJARDO apud SANTOS; OLIVEIRA, 2011, P. 37). 
O Paraná, porém, não ficou incólume ao desenvolvimento econômico e industrial desenvolvido no Brasil como um todo, haja vista que inseriu-se num processo de planejamento econômico e desenvolvimentista: desde aquele projeto denominado por Francisco de Magalhães Filho como projeto paranaense de desenvolvimento, aplicado desde 1961, até o recente desenvolvimento do Programa Paraná Competitivo, implementado pela administração governamental do Estado desde o ano de 2011.

A relação que se estabelece entre Governo e iniciativa privada no Paraná é notada no Estado em diversas frentes. No desenvolvimento de políticas de desenvolvimento econômico ou de benefícios para a atividade produtiva, nota-se a grande participação do aparato estatal estadual nos movimentos de descentralização industrial ocorrido no Brasil a partir de 1970 (SANTOS; SILVEIRA, 2011). Ainda nesta época, através de um reordenamento territorial promovido pelo Estado do Paraná e pela Prefeitura de Curitiba, diversas empresas nacionais e, sobretudo, internacionais foram atraídas tendo como foco a instalação dentro do Estado e da recém-criada Cidade Industrial de Curitiba.

Ensaios de planejamento e do desenvolvimento econômico apoiado pelo Estado do Paraná tiveram um grande avanço a partir do Plano de Desenvolvimento Integrado (PDI) da Região Metropolitana de Curitiba. Criado na década de 1970, buscou reunir o governo estadual e os governos municipais em torno de um planejamento da Região Metropolitana de Curitiba, hoje composta por 29 municípios (COMEC, 2006).

Analisar a disposição geográfica das empresas internacionais que têm se instalado recentemente no Estado é relevante, pois conta com o apoio, para instalação, de espaços definidos ou negociados junto ao governo estadual. Esta é uma das mais relevantes questões relacionadas a este processo de ingresso no território paranaense, pois é um dos principais indicativos da maneira como o próprio Governo enxerga o território.

Por sua vez, ao estudarmos atividades de Governos Estaduais em geral, e do Estado do Paraná em específico, nos leva a referenciar novas formas como estas entidades se enquadram na lógica atual da globalização. A lógica imbricada na atuação

Conjuntura Global, Vol.3, n.1, jan./mar., 2014, p. 28-42. 
atual de empresas transnacionais é representada pelo descolamento da produção econômica e da localização:

\begin{abstract}
A globalização da economia, da mobilidade do capital e a tecnologia do transporte e das comunicações eliminaram muitos dos vínculos entre localização e produção (...) reduzindo a dependência das empresas a respeito da sua proximidade das matérias primas ou vias marítimas de comunicação (KEATING, 2000, p. 12) ${ }^{7}$.
\end{abstract}

Desta forma, analisar de qual forma ocorre a racionalidade deste processo, bem como de qual forma se dá a seleção das localizações sugeridas na atração de investimentos estrangeiros, nos dá uma forte ideia de como estamos sendo representados, e de qual forma o território paranaense é apresentado como uma vantagem competitiva que permite a instalação destas empresas. Reconhecemos, neste caso, o vazio aberto pelos governos centrais dentro desta realidade globalizatória que "põe mais ênfase na competitividade nacional e menos no equilíbrio regional, deixando que este vazio seja ocupado pelos governos subestatais" 8 (p. 14).

Porém, é neste mesmo processo em que se encontra a própria estrutura estatal, ou governamental. A lógica de atração dos investimentos estrangeiros é perigosa, mas, efetivamente, uma das mais buscadas por governos regionais (KEATING, 2000, p. 2223). Os investimentos estrangeiros diretos são compreendidos como oportunidades para "criação de empregos e crescimento económico, assim como a aparição de novos setores económicos, mas implica o risco da dependência e da insegurança, já que o capital pode ir embora tão facilmente como chegou [ao território]” 9 (p. 15).

Entre 2011 e 2012, o Brasil foi o principal foco de investimentos estrangeiros diretos na América Latina - segundo o Relatório 2012 da revista especializada Financial Times, o país atraiu 491 projetos de investimentos estrangeiros diretos, o que

\footnotetext{
${ }^{7}$ No original, "La globalización de la economía, la movilidad del capital y la tecnología del transporte y de las comunicaciones han eliminado muchos de los vínculos entre localización y producción (...) reduciendo la dependencia de las empresas respecto de su proximidad a las materias primas o vías de comunicación marítimas."

8 "(...) ponen más énfasis en la competitividad nacional y menos en el equilibrio regional, dejando que este vacío lo llenen los gobiernos subestatales."

9 “(...) creación de empleos y crecimiento económico, así como la aparición de nuevos sectores económicos, pero conlleva el riesgo de la dependencia y la inseguridad, ya que el capital puede marcharse tan fácilmente como llegó."
}

Conjuntura Global, Vol.3, n.1, jan./mar., 2014, p. 28-42. 
contabiliza um total de $36 \%$ destes projetos que estão sendo realizados na região e no Caribe, sendo que em toda a região a soma dos investimentos realizados chegou a US\$ 137 bilhões naquele período (fDi Intelligence, 2012, p. 11-12).

Desta forma, o Governo Estadual do Paraná vem atuando para inserir-se nesta nova rota de investimentos. Segundo fontes oficiais do governo, nos últimos dois anos, o Estado atraiu R $\$ 20$ bilhões e gerou mais de mil empregos. Assim, percebe-se a inclusão do mesmo nas lógicas descritas acima ${ }^{10}$. Esta atuação, por si própria, já foi relacionada com uma descrição realizada pelo Estado a respeito de seu território e sua posição geográfica, sendo de extrema importância a análise deste tipo de referência utilizada pelo Governo Estadual neste esforço de atração de investimentos estrangeiros.

As relações entre empresariado e o poder governamental no Paraná já foi discutido de diversas formas, sobre tudo na perspectiva do desenvolvimento da Cidade Industrial de Curitiba e no processo de desenvolvimento econômico do Estado (MAGALHÃES FILHO, op. cit.) Desta forma, desejamos aproximar a pesquisa da questão da abordagem do Governo a respeito de seu território como vantagem competitiva.

Por fim, determinar o recorte espacial do Estado do Paraná nos permite, de forma mais específica, compreender a característica, nesta região, de características dos binômios "desigualdade-diferença e globalização-fragmentação através das relações global-local" (HAESBAERT, 1999, p. 23).

\section{CONSIDERAÇÕES FINAIS}

Este trabalho, motivado pela pesquisa realizada, não pretende apresentar respostas definitivas às questões suscitadas. Mais que isso, pretende ser uma forma de análise a respeito de conceitos fundamentalmente políticos no campo de conhecimento da Geografia, permitindo uma melhor comunicação entre diversas disciplinas acadêmicas na discussão de um tema profundamente impactante na economia e na sociedade do Estado do Paraná.

\footnotetext{
10 PARANÁ. Agência Estadual de Notícias, "Fábrica alemã investirá R\$ 250 milhões nos Campos Gerais", publicada em 22/10/2012, às $19 \mathrm{~h} 40$.
}

Conjuntura Global, Vol.3, n.1, jan./mar., 2014, p. 28-42. 
Ao buscar as bases teóricas da compreensão da relação entre a sociedade e a sua base material, sobretudo através de sua atuação política como base das relações, pudemos criar uma forma de análise que unisse diversos conceitos diferentes para esta análise. Afinal, sociedade, Estado e empresas não vivem em espaços separados, mas sim interagindo entre si continuamente. Assim, compreendemos que a articulação dos conceitos de Poder, Espaço e Território nos auxiliam na análise desta realidade.

\section{REFERÊNCIAS BIBLIOGRÁFICAS}

CASTELLS, Manuel. A Sociedade em Rede. 6a ed. São Paulo: Paz e Terra, 1999.

CORRÊA, Roberto L. Espaço, um conceito-chave na Geografia. In: CASTRO, Iná E. de; GOMES, Paulo C. da C.; e, CORRÊA, Roberto L. Geografia: Conceitos e Temas. 15a Ed. Rio de Janeiro: Bertrand Brasil, 2012.

COMEC - Coordenação da Região Metropolitana de Curitiba. Plano de desenvolvimento integrado da Região Metropolitana de Curitiba: propostas de ordenamento territorial e novo arranjo institucional. COMEC: Curitiba, 2006.

FERNÁNDEZ, Victor R.; AMIN, Ash; e, VIGIL, José Ignacio. Discutiendo el desarrollo regional: desde la emergencia y la institucionalización de la nueva ortodoxia hacia su reconsideración. In: FERNÁNDEZ, Victor R.; AMIN, Ash; e, VIGIL, José Ignacio (orgs.). Desarollo urbano y regional y políticas públicas. Argentina: Miño y Dávila, 2008.

FDI INTELLIGENCE. The fDi Report 2012. Disponível em <http://ftbsitessvr01.ft.com/forms/fDi/report2012/files/The_fDi_Report_2012.pdf>, acessado em 04/11/2012, às $17 \mathrm{~h} 30$.

HAESBAERT, Rogério da C. O Mito da Desterritorialização - Do "Fim dos Territórios" à Multiterritorialidade. 6ํㅡㄹ ed. Rio de Janeiro: Bertrand Brasil, 2011.

HAESBAERT, Rogério. Região, diversidade territorial e Globalização. Revista GEOgraphia. Rio de Janeiro: Ano 1 - № 1: 15-39, 1999.

KEATING, Michael. Regiones y asuntos internacionales: Motivos, oportunidades y estratégias. In: ALDECOA, Francisco; KEATING, Michael (org.). Paradiplomacia : Las relaciones internacionales de las regiones. Madrid: Marcial Pons Ediciones Jurídicas y Sociales, S.A., 2000.

MAGALHÃES FILHO, Francisco de B. B. Da construção ao desmanche: análise do Projeto de Desenvolvimento Paranaense. Curitiba: Editora UFPR, 2011.

MIYAMOTO, Shiguenoli. Geopolítica e poder no Brasil. Campinas, SP: Papirus, 1995.

RAFFESTIN, Claude. Por uma Geografia do Poder. Editora Ática: São Paulo, 1993.

Conjuntura Global, Vol.3, n.1, jan./mar., 2014, p. 28-42. 
SAQUET, Marco A. Estudos territoriais: os conceitos de território e territorialidade como orientações para uma pesquisa científica. In: FRAGA, Nilson C. Territórios e fronteiras (re)arranjos e perspectivas. Florianópolis: Insular, 2011.

SANTOS, Milton. A natureza do espaço: técnica e tempo, razão e emoção. 4⿳亠丷a ed, 17ạ reimpr. São Paulo: Editora da Universidade de São Paulo, 2012.

SANTOS, Milton; e SILVEIRA, María L. O Brasil - território e sociedade no início do século XXI. Rio de Janeiro: Record, 2001.

SOUZA, Marcelo J. L. de. O Território: Sobre Espaço e Poder, Autonomia e Desenvolvimento. In: CASTRO, Iná E. de; GOMES, Paulo C. da C.; e, CORRÊA, Roberto L. Geografia: Conceitos e Temas. 15aㅡ Ed. Rio de Janeiro: Bertrand Brasil, 2012. 